\title{
Lope de Vega, Autos sacramen- tales completos, Los acreedores del Hombre, ed. Daniele Crivellari y J. Enrique Duarte y Del pan y del palo, ed. Alejandra Ulla Lorenzo (vol. 6), Kassel, Edition Reichenberger, 2020, 172 pp. ISBN: 978-3-967280-08-7 *
}

\section{Rocío Alonso Medel}

http://orcid.org/0000-0002-0402-1840

Universidad Complutense de Madrid ESPAÑA

rocioalo@ucm.es

[Hipogrifo, (issn: 2328-1308), 9.2, 2021, pp. 1099-1102]

Recibido: 15-07-2021 / Aceptado: 28-07-2021

DOI: http://dx.doi.org/10.13035/H.2021.09.02.70

El volumen que se reseña es el último resultado ${ }^{7}$, hasta el momento, del proyecto «Autos sacramentales completos de Lope de Vega: Edición, estudio y contexto histórico» (FFI2013-45388-P), liderado por Ignacio Arellano, director del Grupo

* La presente reseña es el fruto de una de las actividades que realicé en la estancia de investigación predoctoral realizada en la Universidad de Navarra, entre junio y julio de 2021, gracias a la concesión de una estancia breve (Conv. 2021 PINVES EB15/21) del contrato predoctoral (CT42/18-CT43/18) que disfruto en la Universidad Complutense de Madrid (Departamento de Literaturas Hispánicas y Bibliografía).

1. En la actualidad, contamos con un total de 6 ediciones críticas de autos sacramentales lopianos, editadas por la prestigiosa editorial alemana Reichenberger, a saber: (vol. 1) Las bodas entre el Alma y el Amor divino y El hijo pródigo, a cargo de José Enrique Duarte, en 2017; (vol. 2) La maya y El viaje del Alma por Juan Manuel Escudero Baztán, en 2017; (vol. 3) La privanza del hombre a cargo de Victoriano Roncero y El nombre de Jesús por Ignacio D. Arellano Torres, en 2018; (vol. 4) Las hazañas del segundo David y El Misacantano de José Enrique Duarte, en 2018; (vol. 5) El heredero del cielo de Elena E. Marcello y El niño pastor por Fernando Rodríguez Gallego, en 2019; y (vol. 6) el volumen aquí reseñado (2020). Cada una de ellas se edita por un especialista en la materia, como se puede comprobar en los nombres aludidos. Reseñas anteriores de otros volúmenes pueden consultarse en: Hilarie Kallendorf, Bulletin of 
de Investigación Siglo de Oro (GRISO) de la Universidad de Navarra, y coordinado por José Enrique Duarte, investigador del GRISO. El proyecto, subvencionado por el Ministerio de Economía, Industria y Competitividad del Gobierno de España, tiene como propósito elaborar la edición crítica de todos los autos sacramentales que elaboró el Fénix de los Ingenios.

Además del colosal número de comedias que proyectó el madrileño² ${ }^{2}$ ideó cuarenta autos sacramentales. Estos textos conforman un corpus representativo del género, pero no inabarcable. Son un testimonio de referencia para entender la evolución de este distinguido corpus literario y artístico de la historia de la literatura española. Por lo común los autos sacramentales conforman un género escasamente conocido del que se suelen tener vagas y equívocas referencias ${ }^{3}$. Así, dos de los autos lopianos se presentan en este sexto volumen: Los acreedores del Hombre, auto «de redención»; y Del pan y del palo, auto de «El papel de la Iglesia en la Salvación», en palabras de Philip Howard Martin4. La edición crítica corre a cargo de investigadores con un amplio conocimiento en la literatura de los Siglos de Oro y en la edición de textos de la época. El primero de los autos - Los acreedores del Hombre- lo examinan y editan José Enrique Duarte (Universidad de Navarra) y Daniele Crivellari (Università degli Studi di Salerno). En todo momento, ambos investigadores especifican cada una de las partes de las que se han encargado en el estudio de la pieza ${ }^{5}$. El segundo -Del pan y del palo- está a cargo de Alejandra Ulla Lorenzo (Universidad Internacional de La Rioja).

Al igual que en entregas anteriores, el volumen aparece con un estudio introductorio en el que se detalla la información más sobresaliente que presenta cada uno de los textos. Para Los acreedores del Hombre se presenta (a) un estado de la cuestión sobre la autoría de la pieza: existen dos obras con título homónimo6; (b) la métrica del auto sacramental de Lope; (c) una sinopsis argumental del escrito, dividida en sus diferentes versos; (d) el estudio textual de los cuatro impresos y dos

the comediantes, 70.2 (2018), pp. 201-204, para los volúmenes 1 y 2; y Carmen Saen de Casas, Renaissance Quarterly, 73.3 (2020), pp. 1107-1108, para el volumen 3.

2. La recuperación de los distintos textos del Fénix, en la actualidad, se presenta mediante cuidadas y pulcras ediciones críticas elaboradas por el Grupo de Investigación sobre Lope de Vega (PROLOPE) de la Universidad Autónoma de Barcelona. Para buscar distinta información en línea sobre las comedias de Lope: datos bibliográficos, anotaciones pragmáticas, caracterizaciones, observaciones de la obra y ediciones digitales disponibles recomiendo el Proyecto de ARTELOPE: Base de datos y argumentos del teatro de Lope de Vega, dirigido por Joan Oleza Simó, de la Universitat de València, disponible en: $<$ https://artelope.uv.es/\#inicio> [consulta realizada el 11 de julio de 2021].

3. Para ampliar información y entender el funcionamiento del género remito al estudio de Arellano, Ignacio, Estructuras dramáticas y alegóricas en los autos de Calderón, Pamplona / Kassel Universidad de Navarra, Kassel / Reichenberger, 2001

4. Martin, Philip Howard, Los autos sacramentales de Lope de Vega, Ann Arbor, University Microfilms Universal, 2001, pp. 37 y 53-54.

5. Ver nota $(*)$ de la Introducción al estudio del auto en este volumen (p. 9).

6. Nos referimos a la presentada en el volumen y firmada por el Fénix y a la obra homónima adscrita a la pluma de Rojas Zorrilla. 
manuscritos que se localizan $;$ y (e) algunas observaciones de la edición al auto sacramental. Para Del pan y del palo se opta por añadir la fortuna escénica del auto a los epígrafes comunes de los estudios que presenta la colección. Se ofrece: (a) la fecha de composición y distintas representaciones de la pieza; (b) el status quaestiones y argumento del auto; (c) la sinopsis métrica; (d) el estado textual del escrito del que solo se ha conservado un ejemplar del siglo XVII; y (e) alguna nota a los criterios de edición del texto. Como término al estudio introductorio, sendos trabajos incorporan una relación de la bibliografía manejada y una lista de las abreviaturas que aparecen en la edición crítica. Hay que distinguir, asimismo, el acierto al incluir después de cada afirmación la transcripción de la fuente precisa donde se localiza la declaración. Cada investigador especifica el fragmento al que alude y no se limita a añadir la usual referencia al número de página en el que se localiza el concepto o idea aludido. Este aspecto facilita al curioso lector la búsqueda y reafirma la credibilidad de lo expuesto. Acto seguido se apuntan sugerencias que quizá podrían valorarse para entregas futuras, pero que no deslucen la valoración del esfuerzo y el excelente resultado que se presenta en el volumen. Pese a que en cada uno de los autos se incluye la métrica del mismo, se podría añadir algún comentario en el que se vincule el uso de los distintos metros que aparecen en la pieza. De forma análoga, en la edición de Alejandra Ulla, con buen sentido, se agrega mediante corchetes el metro correspondiente que se utiliza en las diferentes partes del auto sacramental. Si se resuelve proceder de este modo, habría que afinar igual con todas las ediciones de los distintos autos sacramentales lopianos.

En su conjunto, el volumen incluye textos perfectamente anotados y puntuados desde el punto de vista de la filología más tradicional. Este resultado revela la muy elogiable labor que han afrontado sus editores al aceptar el trabajo. Si ya es intrincado editar un texto áureo con «ojos de época», la labor de editar un auto sacramental es más compleja, si cabe, debido al deslumbrante universo alegórico que aparece en cada uno de los versos del escrito y que el investigador interpreta. Los editores intentan explicar con detalle la procedencia de las diferentes voces o pasajes que el lector desconoce mediante las notas a pie de página en el propio texto. Para ello, recurren a obras de referencia para la época como Aut. o Cov. (ver notas, pp. 32, 46 62, 119, 127, 158), estudios críticos anteriores dedicados al género (ver notas, pp. 29, 41, 115, 122, 138), alusiones a la Biblia (ver notas, pp. 38, 58, 76, 118, $127,144)$ y menciones con coincidencias de la producción literaria del dramaturgo. Aparecen varios tópicos o loci paralleli frecuentes en la obra de Lope y sus coevos (ver notas, pp. 43, 56, 74, 127, 130, 151). Con el propósito de distinguir las aclaraciones de las distintas variantes que se leen en los testimonios cotejados, al finalizar cada trabajo se presenta el aparato crítico utilizado en el auto sacramental. En este aspecto, ambas ediciones son acordes y consecuentes con sus precedentes.

7. Además de indicar y añadir la descripción de cada testimonio, los editores especifican el ejemplar o ejemplares del texto que han cotejado para la edición crítica que presentan (ver pp. 15-16). 
Acaba el volumen con un conveniente índice de notas común para los dos autos. Así se facilita la tarea de búsqueda del lector para localizar cualquier aspecto en el que esté interesado y comprobar si es un motivo común de los dos textos o no.

Solo nos queda destacar aquí que este proyecto, iniciado en 2017, es todo un acicate para ampliar el conocimiento del universo dramático del Fénix. Esperamos que en un futuro no demasiado lejano los resultados de esta investigación se encuentren alojados en distintos servidores digitales, además de su versión en papel, con el propósito de alcanzar a un mayor número de lectores, estudiantes e investigadores ${ }^{8}$. Por ahora, y mientras que el proyecto progresa, debemos destacar su labor y encomiar sus diferentes entregas, tan completas.

8. Hasta el momento, puede consultarse el texto de las entregas antecedentes a este volumen, vinculados al proyecto de los autos de Lope en el repositorio institucional de la Universidad de Navarra, disponible en: <https://www.unav.edu/web/griso/proyectos/autos-sacramentales-completos-de-lopede-vega> [consulta realizada el 28 de julio de 2021]. 